\title{
The response-shock interval and conditioned suppression of avoidance in rats*
}

\author{
STANLEY R. SCOBIE $\dagger$ \\ State University of New York at Binghamton, Binghamton, New York 13901
}

\begin{abstract}
Rats were trained to avoid unsignaled shocks with response-shock intervals of 30,60 , or 120 sec. When CSs of 60 sec duration paired with unavoidable shocks were then superimposed upon the avoidance baseline, responding decreased during the CS. Reductions in responding resulted in extra shocks which were potentially avoidable in all response-shock interval conditions, with the greatest increase in shocks in the response-shock 30-sec condition. Decrcases in responding were greater when the $C S$ was paired with a $2.0-\mathrm{mA}$ unavoidable shock than with a $1.0-\mathrm{mA}$ shock.
\end{abstract}

Studies of effects of Pavlovian conditional stimuli (CSs) which signal unavoidable shocks (unconditional stimuli or USs) upon unsignaled shock-avoidance responding have often found increases in responding during the CS (e.g., Maier, Seligman, \& Solomon, 1969; Rescorla, 1967; Sidman, Herrnstein, \& Conrad, 1957; Weisman \& Litner, 1969). However, Pomerleau (1970) has recently pointed out that either increases or decreases can occur, depending on the duration of the $\mathrm{CS}$ relative to the amount of time responses postpone shocks on the avoidance schedule. Monkeys responding on an adjusting avoidance schedule usually responded below basal rates when the CS was short relative to the time the avoidable shock could be postponed. When the CS was relatively long, responding was generally higher during the CS. Shimoff (1972) obtained similar results, but with somewhat smaller increases in responding during long CSs. However, in the only direct study of this temporal variable with rats, Brady, Libber, and Dardano (1967) found decreases in avoidance response rates in three of four Ss, even when shock could be postponed for $60 \mathrm{sec}$ relative to a CS duration of $120 \mathrm{sec}$.

The present experiment studied the effects of the response-shock (RS) interval, i.e., the time responses postpone shocks, upon responding during a CS paired with an unavoidable shock US. Groups of four rats were trained to avoid unsignaled shocks with RS intervals of 30,60 , or $120 \mathrm{sec}$. When responding was stable, a noise $\mathrm{CS}$ of $60 \mathrm{sec}$ duration followed by an unavoidable shock US was superimposed upon the avoidance operant. Thus, for the RS 30-sec condition, the CS was twice as long as the RS interval. This relationship required at least two avoidance responses during the CS to avoid all the avoidable baseline shocks. For the RS 60 -sec condition, the RS interval was of exactly the same duration as the

*Preparation of this manuscript was supported, in part, by PHS Research Grant MH 18898-01 from the National Institute of Mental Health.

tReprints may be obtained from the author at the Department of Psychology, State University of New York, Binghamton, New York 13901.
CS. And, for the RS 120 -sec condition, the CS was one-half as long as the RS interval. In this condition, one response, at very most, during the CS was required to avoid all baseline shocks, and, depending upon baseline response rates, often no responses were required to do so. Given these conditions, it might be expected, following Pomerleau (1970), that the RS 120-sec Ss would suppress responding during the CS because they could do so at little or no "cost" in terms of extra shocks. For the RS 30-sec Ss, however, accelerated responding or no change during the $\mathrm{CS}$ might be expected since suppression would "cost" extra shocks.

\section{METHOD}

Subjects

Twelve male hooded rats from Quebec Breeding Farms. Montreal, Quebec, served as Ss. They weighed between 300 and $400 \mathrm{~g}$ and were maintained in individual cages with free access to food and water.

\section{Apparatus}

The Ss were trained and tested in four standard lever chambers enclosed in sound-attenuating chests. The grid floors could be electrified with scrambled shock from a Grason-Stadler E1064GS shock generator.

\section{Procedure}

\section{Baseline Avoidance Training}

Each $S$ was given an initial 6-h avoidance training session. All subsequent sessions were $2 \mathrm{~h}$ in duration. For the initial session, Ss could postpone shocks for $60 \mathrm{sec}$ with each response (RS = $60 \mathrm{sec}$ ). If a $S$ did not respond for $60 \mathrm{sec}$, the shock came on and remained on until a leverpress occurred (cf. Wertheim, 1965). This represents a zero shock-shock (SS) interval in conventional terminology. Shock intensity during the initial session was set at $0.5 \mathrm{~mA}$, and then, as a $\mathrm{S}$ made more avoidance responses, it was increased to $1.0 \mathrm{~mA}$, where it remained for the rest of the experiment.

After the initial 6-h session with the $60-\mathrm{sec}$ RS interval, the Ss were assigned randomly to one of three groups with RS equal to 30,60 , or $120 \mathrm{sec}$, and they were subsequently trained and tested at their assigned RS interval. Throughout the experiment, 

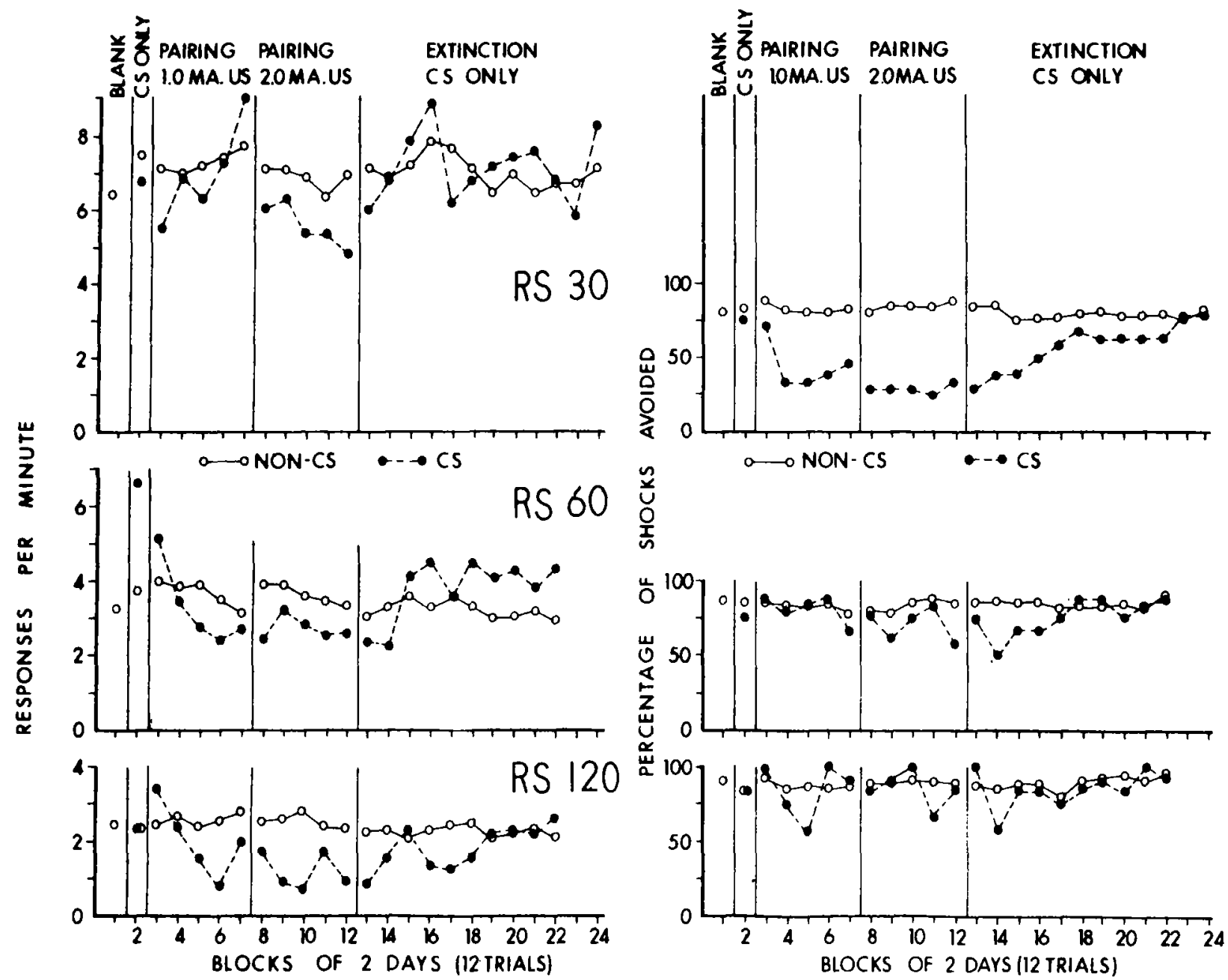

Fig. 1. Median response rates and median percentage shock avoidance for the entire experiment. The top panels represent the RS 30-sec Ss, the middle panels represent the RS 60-sec Ss, and the lower panels represent the RS 120-sec Ss. The blank phase represents the level of performance prior to introduction of any stimuli. The CS-only pretest phase was just 1 day (6 trials); all other data points represent 2 days (12 trials).

the SS interval remained at zero. The Ss were trained in 2-h sessions until responding was stable (about $50 \mathrm{~h}$ ).

\section{CS-US Pairing}

One CS pretest session was given during which six 60-sec CSs were presented at irregular intervals ranging from 15 to $45 \mathrm{~min}$ while the Ss continued to respond on the avoidance schedule. The CS was a 75-dB (re .0002 dynes $/ \mathrm{cm}^{2}$ ) 'white noise. Following the pretest of the CS, six CS trials were programmed daily in the same way while the avoidance contingencies remained in effect, but at the end of each CS, a $0.5-\mathrm{sec} 1.0-\mathrm{mA}$ shock US was delivered. Pairings continued with the $1.0 \mathrm{~mA}$ US following each CS for 10 days. For the next 10 days, a 0.5 -sec 2.0-mA US was programmed at the end of each CS. After a total of 20 days of such pairings, the shock was no longer programmed to follow the CS, and the Ss were tested in this CS extinction condition for 20 more days (25 days for the RS 30-sec group, since these Ss failed to completely extinguish reaction to the $\mathrm{CS}$ within 20 days). Throughout all phases, the baseline avoidance contingencies remained in effect.

\section{RESULTS}

\section{Responding During CS}

Response rates averaged over the entire CS and during the rest of the session are shown for the three RS interval groups in the left panels of Fig. 1. Baseline responding is expressed as responses per minute during the sessions as a whole, with the exception of responding during CS trials and the 60-sec period after each trial. Response rates during the CS periods were, in the absence of CS-US pairings, equivalent to response rates during the session as a whole when data for blank trials were taken during baseline training. For Ss in the RS 30and 120-sec groups, the CS alone had little effect on responding. All four of the RS 60-sec Ss, however, responded at a somewhat higher rate during the pretested CS than during the rest of the session.

When the CS was paired with the 1.0-mA US, the RS 30-sec Ss showed little change in responding over the 
entire CS, while the RS 60-sec and RS 120-sec Ss responded at somewhat lower rates during the CS than during the no-CS baseline (chi square $=6.12, \mathrm{p}<.025$ ). With the 2.0-mA US, all the groups showed response suppression during the CS. Eleven of the 12 Ss responded less during the CS than during the rest of the session (chi square $=6.75, p<.01$ ). One $S$ in the RS 60-sec group increased responding during the CS. Careful examination of cumulative records and sampled interresponse time distributions revealed no differences in the pattern of responding over the 60-sec CS.

During Pavlovian extinction when the CS was presented without the US, response rates during the CS recovered to baseline after about six sessions in all groups. Overall, six animals responded somewhat more during the CS and six responded somewhat less, indicating no reliable systematic effect by the end of the extinction phase.

\section{Baseline Responding}

There were no systematic effects of the CS-US pairings on baseline avoidance response rates. As might be expected, response rates for the RS 30-sec Ss were higher than those for the RS 60-sec and RS 120-sec Ss. There was no overlap in baseline response rates for Ss in the RS 30-sec and RS 120-sec groups.

\section{Shock Avoidance During CS}

The right-hand panels of Fig. 1 show the average percentage shock avoidance data. This was computed as: percentage shock avoidance $=100-[$ (shocks received per $\mathrm{min}) /(1 /$ RS interval in min)]. Since all Ss responded to terminate shock as soon as it was presented, the number of shocks is equal to the number of SS intervats presented. The most striking finding in these data is the large decrement in shock avoidance during the CS for the RS 30-sec Ss in both the 1.0-mA US and 2.0-mA US phases. All $S s$ in this group avoided far fewer shocks during the CS than during baseline responding. There was some tendency for the Ss in the RS 60-sec group to avoid fewer shocks during the CS in the $2.0-\mathrm{mA}$ phase, and three of four Ss in the RS 120-sec group avoided fewer shocks during the CS in this phase. However, the magnitude of this latter effect was small, as can be seen in Fig. 1.

Shock avoidance performance recovered during the CS extinction phase somewhat more slowly than did response rates (Fig. 1). However, by the end of the extinction phase, avoidance percentages during the CS equaled baseline avoidance percentages.

\section{DISCUSSION}

The major finding of this experiment, that unsignaled avoidance responding is suppressed during a CS which is equal to or longer than the RS interval even when suppression results in extra potentially avoidable shocks, has been replicated several times (Brady et al, 1967: Roberts \& Hurwitz, 1970; Scobie, 1972). This is inconsistent with Pomerleau's (1970) generalization that "... when baseline shocks result from response decrements during the CS, responding will assume high or 'facilitated' rates for a large proportion of the time that the stimulus is present [p. 20]." There were, of course, numerous differences between these studies and Pomerleau's, not the least of which was the use of rats vs monkeys.

There seemed to be no important differences in the magnitude of decreases in responding during the CS as a function of the RS interval, and responding was suppressed when the CS was longer, equal to, or shorter than the RS interval. This suggests that, in this situation at least, CS duration relative to the time shock can be postponed (i.e., the RS interval) is of minor importance in determining the reaction to the CS. The finding of no change in the pattern of responding over the $60-\mathrm{sec}$ CS is consistent with earlier work (Scobie, 1972). This suggests that rats are less prone than monkeys or dogs to show a complex pattern of response rate changes during a moderately long aversive CS (cf. Pomerleau, 1970; Rescorla, 1967). There were, of course, large increases in the number of potentially avoidable shocks during the CS in the RS 30-sec condition. This was because response suppression in the RS $30-\mathrm{sec}$ condition necessarily resulted in extra baseline shocks, while in the RS 120 -sec condition this was much less likely to occur because one response could postpone shock for $120 \mathrm{sec}$ and the CS was only $60 \mathrm{sec}$ in duration.

All studies (with just one exception: Blackman, 1970) in which a CS-shock pairing was superimposed upon an avoidance operant have produced suppression when the operant was a leverpress and rats were used as Ss. Shuttle and wheel turn operants can be accelerated (Scobie, 1972; Weisman \& Litner, 1969) and suppressed (Scobie, 1972). Thus, it appears that a strong test of the notion that CSs short relative to the RS interval produce suppression and relatively long CSs produce acceleration requires an operant which will, under some circumstances, increase during an aversive CS.

The finding that increasing the US intensity resulted in greater suppression of avoidance responding is reasonably well documented (Scobie, 1972). Our understanding of "why" such suppression occurs is not good. It does not appear to be due to operant punishment by the US, and it is comparable to the suppression seen with appetitive operants and aversive CSs. Discriminative factors (cf. Blackman, 1970) may be important particularly if discrimination of the US from the avoidable shocks is difficult. Failure to discriminate the US from the avoidable shock might well result in adventitious avoidance responding (e.g., Kelleher, Riddle, \& Cook, 1963). In fact, the accelerated avoidance responding seen during relatively long CSs (Pomerleau, 1970) might be due, in part, to the animals' 
failure to associate the CS with the US at long CS-US intervals.

\section{REFERENCES}

Blackman. D. E. Conditioned suppression of avoidance behavior in rats. Quarterly Journal of Experimental Psychology: 1970. 22, 547-553.

Brady, J. V.. Libber, S.. \& Dardano. J. Some effects of a pre-aversive stimulus on avoidance behavior. Technical Report No.67-14. Space Research Laboratory. Department of Psychology, University of Maryland. 1967.

Kelleher, R. T., Riddle, W. C.. \& Cook, L. Persistent behavior maintained by unavoidable shocks. Journal of the Experimental Analysis of Behavior, 1963.6. 507-517.

Maier, S. F., Seligman. M. E. P.. \& Solomon. R. L. Pavlovian fear conditioning and learned helplessness: Effects on escape and avoidance behavior of (a) the CS-LS contingency and (b) the independence of the US and voluntary responding. In B. A. Campbell and R. M. Church (Eds.), Punishment and arersive behavior. New York: Appleton-Century-Crofts, 1969.

Pomerleau. O. F. The effects of stimuli followed by response-independent shock on shock-avoidance behavior. Journal of the Experimental Analysis of Behavior, 1970, 14, 11-21.
Rescorla. R. A. Inhibition of delay in Pavlovian fear conditioning. Journal of Comparative \& Physiological Psýchology. 1967.64, 114-120.

Roberts. A. E.. \& Hurwitz, H. M. B. The effect of a pre-shock signal on a free-operant avoidance response. Journal of the Experimental Analysis of Behavior. 1970. 14, 331-340.

Scobie, S. R. Interaction of an aversive Pavlovian conditioned stimulus with aversively and appetitively motivated operants. Journal of Comparative \& Phy'siological Psychology, 1972, 79. $171-188$.

Shimoff, E. Avoidance responding as a function of stimulus duration and relation to free shock. Journal of the Experimental Analysis of Behavior. 1972, 17, 451-461.

Sidman. M., Herrnstein, R. J., \& Conrad, D. G. Maintenance of avoidance behavior by unavoidable shocks. Journal of Comparative \& Physiological Psychology, 1957, 50, 553-557.

Weisman. R. G., \& Litner. J. S. Positive conditioned reinforcement of Sidman avoidance behavior in rats. Journal of Comparative \& Physiological Psychology. 1969. 68. 597-603.

Wertheim. G. A. Some sequential aspects of IRTs emitted during Sidman-avoidance behavior in the white rat. Journal of the Experimental Analysis of Behavior. 1965, 8, 9-15.

(Received for publication July 6. 1972; revision received August 25, 1972.) 